\title{
Aplicativos gratuitos como ferramenta tecnológica no desenvolvimento do Cálculo \\ Mental: uma metodologia lúdica para o Ensino Fundamental
}

\author{
Free apps as technological tool in the development of Mental Calculus: a playful \\ methodology for Primary Education
}

\begin{abstract}
Liliane Silva Faria Barreto
Universidade Estadual do Norte Fluminense (UENF), Laboratório de Ciências Matemáticas Programa de Pós-Graduação Profissional em Matemática, Campos dos Goytacazes, RJ, Brasil lilifaria@hotmail.com

Nelson Machado Barbosa Universidade Estadual do Norte Fluminense (UENF), Laboratório de Ciências Matemáticas Campos dos Goytacazes, RJ, Brasil barbosa@uenf.br
\end{abstract}

\section{Informações do Artigo}

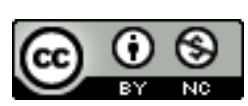

Histórico do Artigo

Submissão: 31 de março de 2018.

Aceite: 03 de maio de 2018.

\section{Palavras-chave}

Cálculo Mental

Jogos Matemáticos

Aplicativos Gratuitos

\section{Resumo}

O objetivo principal deste artigo é investigar e mostrar como o uso de aplicativos gratuitos com conteúdos matemáticos podem colaborar para o desenvolvimento do raciocínio lógico do aluno, através de uma sequência de atividades que estimulem o Cálculo Mental aplicado às operações básicas da aritmética. $\mathrm{O}$ trabalho teve caráter qualitativo, com realização de uma pesquisa de campo, e foi realizado com duas turmas de $6^{\circ}$ ano do Ensino Fundamental da Prefeitura Municipal de Macaé, no Estado do Rio de Janeiro. A utilização dos aplicativos gratuitos foi feita por meio de tablets, possibilitando um contato direto do aluno com alguns aplicativos selecionados, que proporcionaram o desenvolvimento do Cálculo Mental. Tendo como base um planejamento, os alunos testaram e construíram habilidades por meio de jogos e explicações fornecidas pelos aplicativos, juntamente com possíveis intervenções pedagógicas, apresentando as variadas estratégias do Cálculo Mental. O uso desses recursos tecnológicos que os alunos têm muito contato, mas que ainda não haviam experimentado como ferramenta educacional, foi muito positivo, e ao decorrer da pesquisa os alunos tornaram-se mais confiantes com os conteúdos e habilidades desenvolvidas e se mostraram interessados pela matemática.

\section{Abstract}

The main objective of this article is to investigate and show how the use of free apps with mathematical contents can contribute to the development of the student's logical reasoning through a sequence of activities that stimulate the mental calculus applied to the basic operations of arithmetic. The work had a qualitative character, with the accomplishment of a field research, and was carried out with two classes of 6th grade of the Elementary School of Macaé City Hall, in the State of Rio de Janeiro. Students who have distorted age-series, great learning difficulties, and a great lack of interest. The use of the free apps was done through tablets, allowing a direct contact of the student with some selected apps, that provided the development of the mental calculus. Based on a planning, students tested and constructed skills through games and explanations provided by the applications, along with possible pedagogical interventions, presenting the various strategies of mental calculus. The use of these technological resources that the students have a lot of contact with but which they had not yet tried as an educational tool was very positive, and in the course of the research the students became more confident with the contents and skills developed and much more interested in mathematics. 


\section{Introdução}

Atualmente, um dos maiores desafios dos educadores é tornar suas aulas mais atrativas, buscando a atenção e o interesse de seus alunos. Em vista de longos estudos e reflexões, percebe-se que a melhor forma para alcançar esses objetivos é mostrar ao aluno o prazer do raciocínio e o quanto sua mente é capaz de desenvolver habilidades para solucionar problemas. Optamos pelo trabalho com o Cálculo Mental, há tempos recomendado nas propostas pedagógicas e curriculares do ensino da matemática no Brasil, como é verificado em Valente (2004), que destaca a importância de acostumar o aluno à prática dos cálculos mentais, tornandoo seguro e desembaraçado nas operações numéricas, sendo necessário que ele compreenda bem o alcance e a natureza das operações elementares e adquira habilidade crescente no modo de aplicá-las. Por conseguinte, ao apresentar as estratégias do Cálculo Mental para as operações fundamentais, treiná-las e aplicá-las com procedimentos metodológicos coerentes, pretende-se trazer segurança para aluno, para que ele se sinta capaz de aprender tais operações e consequentemente tenha os conhecimentos básicos para aprender qualquer outro conteúdo de matemática.

A utilidade do tema vai além da sala de aula, pois não há lugar no qual se utilize tanto os cálculos mentais como nas situações cotidianas. Então, dar esse estímulo aos alunos significa, também, torná-los confiantes dentro e fora da escola, desenvolvendo o seu raciocínio lógico e seu senso crítico.

Neste artigo, todos os benefícios do Cálculo Mental serão trabalhados com recursos tecnológicos: O hardware, com a utilização de tablets, e os softwares, que são os aplicativos gratuitos. Ao incluir tais recursos como ferramenta para o ensino e aprendizagem, leva-se a modernidade da era tecnológica para dentro da sala de aula, trazendo novas possibilidades para os alunos, tendo como objetivo maior despertar o interesse pelo processo de aprendizagem e garantir a qualidade no ensino.

Alunos do $6^{\circ}$ ano foram o público alvo deste trabalho. A escolha está baseada, principalmente, na deficiência de conteúdos que os alunos trazem dos primeiros anos do Ensino Fundamental, fato que se transforma em um problema crucial para os professores. Nesse contexto, a escolha do tema justifica-se, pois ao trabalhar um conteúdo tão fundamental para esses alunos, podemos corrigir as possíveis falhas dos anos anteriores, revisando os conteúdos, e assim dar condições iguais de aprendizagem a todos.

O presente artigo está organizado em mais três seções. Na seção 2, apresenta-se a fundamentação teórica sobre o tema, são apresentados conceitos, características e potencialidades do Cálculo Mental, além do discurso sobre a necessidade de mudanças na educação que passem pelas Tecnologias de Comunicação e Informação (TIC). Ainda nessa seção, é abordado o conceito de aprendizagem móvel, especificamente o uso de aplicativos gratuitos como ferramenta do desenvolvimento de conceitos matemáticos. Na seção 3, discorre-se 
acerca da metodologia da pesquisa, apresentando os softwares ou aplicativos utilizados. Nessa seção também é apresentado o desenvolvimento da pesquisa: as atividades propostas, as etapas e a temática de cada aula. Por fim, na seção 4, são apresentadas as análises dos resultados obtidos.

\section{Fundamentação Teórica}

A falta de autonomia em alguns alunos diante de um problema matemático, envolvendo as operações aritméticas, nos remete a reflexão da incompreensibilidade discente nas ideias envolvidas nessas operações, os quais não atribuem nenhum significado aos algoritmos que utilizam constantemente. Nesse contexto, podemos afirmar que o fato de saber fazer operações aritméticas não implica em aprendizagem matemática significativa, ou seja, é necessário saber o real significado dos cálculos e na compreensão dos conceitos envolvidos.

Por isso, nesta seção será discutido o conceito do Cálculo Mental e a Tecnologia, visando o ensino e aprendizagem em Matemática.

\subsection{Cálculo Mental}

Há várias definições de Cálculo Mental, algumas muito similares e outras com algumas percepções distintas. Na simplicidade da expressão, pode-se dizer que é o cálculo que usa a mente. Para Taton (1969), o Cálculo Mental e o cálculo escrito são semelhantes uma vez que ambos utilizam a mesma conexão de operações, calcular de cabeça ou calcular com a cabeça. Já Parra (1996) diz que sua concepção de Cálculo Mental não exclui o lápis e o papel, que podem ser usados em registros intermediários em um processo de Cálculo Mental. Ela apresenta suas definições para os tipos de cálculos, diferenciando o chamado cálculo mecânico ou automático que utiliza apenas o algoritmo, usando sempre os mesmos procedimentos sejam quais forem os números tratados, do cálculo pensado ou refletido, que seleciona, dentre vários, o procedimento mais adequado para cada situação. Parra (1996) afirma que a expressão Cálculo Mental pode ter muitos significados, dividindo opiniões, provocando dúvidas e expectativas, fornecendo sua definição com um sentido mais amplo: "Entenderemos por Cálculo Mental o conjunto de procedimentos em que, uma vez analisados os dados a serem tratados, esses se articulam, sem recorrer a um algoritmo preestabelecido para obter resultados exatos ou aproximados" (PARRA, 1996, p. 195).

Em Afonso (1994, p. 38), a expressão Cálculo Mental refere-se ao cálculo de cabeça, o de memória (sem ajuda externa) com dados exatos. No sentido mais amplo, inclui a adaptação mental dos artifícios formais e os métodos de recontagem. Acredita-se que usar o termo "mental" para se referir apenas ao tipo de cálculo sem apoio escrito não é muito apropriado. No sentido exato, em todo cálculo se faz uso da mente, mas na prática, o significado que se dá ao Cálculo Mental pode se considerar como estabelecido universalmente. Quando se fala sobre métodos do 
Cálculo Mental, deve ser entendido que se trata dos métodos histórico-intrínsecos usados na literatura e que não utilizam outros dispositivos além da própria elaboração simbólica.

$\mathrm{Na}$ definição dos parâmetros Curriculares Nacionais de Matemática do $1^{\circ}$ ao $5^{\circ}$ ano, "podese dizer que se calcula mentalmente quando se efetua uma operação, recorrendo-se a procedimentos confiáveis, sem registros escritos e sem a utilização de instrumentos" (BRASIL, 1997, p. 76).

Ao analisarmos as definições de alguns autores sobre o Cálculo Mental, percebemos que a principal intenção é diferenciá-lo do cálculo usual de algoritmos, que consideram um cálculo mecânico, não pelo uso do lápis e papel, mas por não possuir as opções de análise e escolhas que o Cálculo Mental oferece.

Mas qual seriam as vantagens de se trabalhar o Cálculo Mental? As opiniões dos pesquisadores estão no sentido de incentivar o desenvolvimento do Cálculo Mental na escola e consequentemente no cotidiano. Taton (1969) salienta que o Cálculo Mental desenvolve nas crianças qualidades de ordem, de lógica, de reflexão e de memória, contribuindo para a sua formação intelectual e fornecendo-lhes ferramentas para efetuarem cálculos simples sem recurso da escrita e, desse modo, preparando-as para o dia-a-dia. O autor refere ainda que, através do Cálculo Mental, a criança trabalha simultaneamente a memória e a concentração, desenvolvendo a memória dos números, o que a obriga a tomar um contato mais próximo com a individualidade de cada número, levando-a progressivamente a empregar, em diversos casos, simplificações operatórias.

Grande parte do cálculo realizado fora da escola é feito a partir de procedimentos mentais. A habilidade esperada no Ensino Fundamental é que o aluno saiba calcular com agilidade, utilizando-se de estratégias pessoais e convencionais, e saiba verificar resultados. A calculadora não substitui o cálculo mental e escrito, já que eles estarão presentes em muitas outras situações. Os procedimentos de cálculo mental constituem a base do cálculo aritmético que se usa no cotidiano. (BRASIL, 1997, p. 76-77).

O Cálculo Mental não deve ser associado às propostas didáticas antigas, nas quais se exaltavam a memorização e a rapidez nas operações, muitas vezes, sem as devidas compreensões. O que se pretende trabalhar no Cálculo Mental é o desenvolvimento gradativo, cujo o aluno é levado a pensar nas estratégias, argumentar e explorar, se tornando mais seguro, conhecendo cada vez mais o campo numérico e suas estruturas.

Observa-se que há inúmeras vantagens na inclusão do Cálculo Mental nas aulas, como afirmam os pesquisadores citados. Porém, são grandes os desafios em convencer os educadores e alunos, já acostumados ao ensino tradicional, sobre a importância desse desenvolvimento, que deve começar nos anos iniciais do Ensino Fundamental. Ralston (2000) propõe que haja ênfase na aritmética mental para os primeiros anos de escolaridade, a partir do momento em que é introduzida pela primeira vez uma ideia aritmética para além da contagem (por si só, uma atividade mental, claro). Isto significa que à medida em que é apresentada uma operação 
aritmética, é de se esperar que as crianças façam cálculos mentais com essa operação em variadas e substanciais experiências em fase pré-escolar.

Para Parra (1996, p. 201), o Cálculo Mental também deve ser introduzido na escola primária. A autora justifica o seu posicionamento ao apresentar algumas hipóteses didáticas, as principais são: (i) "As aprendizagens no terreno do Cálculo Mental influem na capacidade de resolver problemas", (ii) "O Cálculo Mental aumenta o conhecimento no campo numérico", (iii) "O trabalho do Cálculo Mental habilita para uma maneira de construção do conhecimento que, a nosso entender, favorece uma melhor relação do aluno com a matemática" e (iv) "O trabalho de cálculo pensado deve ser acompanhado de um aumento do cálculo automático".

A proposta de grande parte dos autores citados neste artigo é a de que os discentes devem desenvolver essas estratégias desde os anos iniciais, para que a autonomia desse aluno seja construída gradualmente. Nesse sentido, Parra (1996, p. 208) fundamenta seus estudos em um documento sobre a Educação Primária da Espanha, que diz:

A construção progressiva do conhecimento matemático trafegará por uma via indutiva, tomando como dado primordial a própria atividade do aluno e utilizando suas intuições, tentativas e aproximações heurísticas - estratégias pessoais elaboradas pelos alunos para enfrentar tarefas e situações formuladas - como ponto de partida de uma reflexão que conduza, de maneira progressiva, a formulações mais formais e dedutivas.

Entre os objetivos gerais desse documento, Parra (1996) destaca que ao final da Educação Primária, os alunos deverão ter desenvolvido a capacidade de, entre outras coisas, elaborar e utilizar estratégias pessoais de Cálculo Mental para a resolução de problemas simples, a partir de seu conhecimento das propriedades de numeração e das quatro operações básicas. Para que tal objetivo seja alcançado, o professor deve diagnosticar o nível que seus alunos se encontram, e a partir daí realizar um trabalho de resgate e desenvolvimento de tais estratégias em atividades específicas.

Diante de tantos aspectos favoráveis em relação ao trabalho com Cálculo Mental nas escolas em todas as fases do ensino, nos convencemos de que esse caminho pode levar a uma mudança na Educação Matemática atual, em especial aqui no Brasil, onde se constatou que o Cálculo Mental tem sido deixado de lado até nos anos iniciais, comprometendo toda uma sequência de aprendizagem, resultando em um analfabetismo matemático sistematizado, principalmente nas escolas públicas Municipais e Estaduais. Isso pode ser comprovado em exames nacionais, como na Prova Brasil, ou em exames internacionais, como no Programa Internacional de Avaliação de Estudantes (PISA), nos quais o Brasil sempre ocupa os últimos lugares no desempenho em matemática.

\subsection{A Tecnologia e o Ensino de Matemática}

O uso da tecnologia especificamente para o ensino da matemática é assunto de muitas pesquisas, projetos e biografia. No livro "Explorando a Matemática com Aplicativos 
Computacionais", encontramos embasamento sobre o tema, as autoras propuseram algumas atividades similares tendo em vista que foi realizado nesta pesquisa.

As pesquisadoras destacam a necessidade do uso de recursos tecnológicos na escola, aliados à pedagogia para propiciar a construção e consolidação do conhecimento. No entanto, elas ressaltam que esse é um grande desafio, já que os recursos por si só não têm caráter educacional, e por isso tem sido fator de estudos e projetos para adequação a essa nova abordagem pedagógica de integração das Novas Tecnologias de Informação e Comunicação (NTIC) à educação com o objetivo principal de melhorar a qualidade do ensino.

O ensino da Matemática tem seguido essa perspectiva, como mostra o relatório publicado pelo Joint Mathematical Council of the United Kingdon, por Clark-Wilson et al. (2011, p. 7), apud Carreira e Amado (2015, p. 10), sobre Tecnologias Digitais e Educação Matemática:

O currículo e a avaliação em matemática escolar devem exigir explicitamente que todos os jovens se tornem proficientes no uso de tecnologias digitais para fins matemáticos. [...] Para ocorrer o desenvolvimento de experiências de aprendizagem enriquecidas tecnologicamente, ao nível da sala de aula, a mudança tem de ser apoiada pelos dirigentes escolares e acompanhada por oportunidades sustentadas de desenvolvimento profissional para os professores.

Afirmamos que os recursos tecnológicos para a Educação Matemática têm evoluído bastante, principalmente os softwares, que contribuem para o desenvolvimento de programas, pacotes e aplicativos digitais com objetivos específicos na aprendizagem matemática. Porém, o destaque maior deve estar nos recursos humanos, nos professores e nos alunos, que completam o "pacote" de recursos necessários para as transformações. O professor como ponte entre os recursos disponíveis e o ensino, os alunos com seu contexto histórico-cultural e interesse. Acredita-se que o envolvimento dos alunos em relação à matemática pode ser recuperado através do uso das Tecnologias de Informação e Comunicação (TIC), desde que esse uso não seja um simples acessório para o professor realizar o mesmo trabalho de sempre, mas sim um trabalho completo que transforme informações em conhecimento pleno. Assim, afirmam Carreira e Amado (2015, p. 13):

\footnotetext{
Diante desse contexto, não basta levar o computador ou o tablet para a sala de aula; é necessário que se tenha bem definido, anteriormente, o que se pretende fazer com a tecnologia. A utilização da tecnologia em sala de aula difere bastante da utilização que dela fazemos no dia a dia. Dessa forma, o planejamento, a colocação de objetivos, a escolha de materiais, a seleção de tarefas, a antecipação de questões, ganham uma dimensão central na prática do professor com recursos tecnológicos.
}

$\mathrm{Na}$ prática, os recursos tecnológicos permitem aos alunos explorarem os conceitos, de modo que todos, a seu tempo, compreendam o conteúdo através de experiências e diferentes formas de resolução das questões (como operar, contar, manipular, visualizar etc.). Destaca-se também a importância da ação direta do professor, que propõe questões e desafios para "estimular a ação dos alunos sobre os conceitos, raciocínio, a compreensão, o registro de resultados e a sistematização de conclusões" (CARREIRA; AMADO, 2015, p. 15). 
Sob essa perspectiva, ressaltamos o uso de aplicativos educacionais nos tablets como uma porta de entrada de integração da Educação Matemática e Tecnológica. Os motivos que justificam o uso dos recursos escolhidos poderão ser observados na próxima seção.

\section{Metodologia}

O presente trabalho é uma pesquisa qualitativa, na qual optamos pela pesquisa de campo com características de pesquisa-ação.

Segundo Lehfeld (1991), a pesquisa é como inquisição, o procedimento sistemático e intensivo que tem por finalidade descobrir e interpretar fatos que estão inseridos em uma determinada sociedade. Sobre os procedimentos qualitativos, Creswell (2007, p. 184) diz que "se baseiam em dados e usam estratégias diversas de investigação". Ainda sobre as características de pesquisa de campo, Fonseca (2002) afirma se caracterizar pelas investigações em que se realiza coleta de dados junto a pessoas, com recursos de diferentes tipos de pesquisa, como a pesquisa-ação, que pressupõe uma participação planejada do pesquisador na situação problemática a ser investigada. $\mathrm{O}$ processo de pesquisa recorre a uma metodologia sistemática, no sentido de transformar as realidades observadas, a partir da sua compreensão, conhecimento e compromisso para a ação dos elementos envolvidos na pesquisa.

Sendo assim, justificam-se as escolhas metodológicas desta investigação por coletar dados diretamente na Escola e com os alunos que apresentavam grande dificuldade em matemática, especialmente com as quatro operações básicas da aritmética. Além disso, a proposta de estudo analisa esses dados, propondo o Cálculo Mental como estímulo para uma melhora na relação do aluno com a disciplina, através de uma abordagem diferente, que utiliza a tecnologia para o desenvolvimento do Cálculo Mental, objetivando produzir uma melhora significativa no ensino-aprendizagem dos sujeitos da pesquisa.

\subsection{Os Recursos Tecnológicos: Aplicativos Selecionados}

Nesta pesquisa, o hardware escolhido foi o tablet, um dispositivo móvel e portátil, que não requer o uso de um laboratório específico. Além disso, destaca-se que o tablet é acessível financeiramente, semelhantemente ao smartphone, recurso mais comum entre a população em geral, incluindo os alunos. A sua capacidade de armazenamento de aplicativos, e a possibilidade de poder utilizá-los posteriormente sem ser necessário acesso à internet também contribuíram para a eleição do dispositivo que seria utilizado durante a pesquisa. Entre outros atrativos, esse foi o dispositivo escolhido, uma ferramenta em formato de prancheta que pode ser usada para acesso à internet, organização pessoal e de arquivos digitais, para atividades de trabalho ou de entretenimento. Sua tela, que ocupa quase toda a área útil, é sensível ao toque (touchscreen) e funciona como o principal meio de input de dados e informações. Apresenta ainda funcionalidades de um notebook e a praticidade de um smartphone, sem ser nenhum dos dois. O tablet chega 
para motivar os alunos a explorar mais os conteúdos, criar momentos de reflexão, tirar dúvidas e outras atividades mais produtivas (CERQUEIRA, 2014).

A seguir, apresentaremos os principais aplicativos matemáticos que foram selecionados para aplicar as atividades sobre Cálculo Mental com alunos do $6^{\circ}$ ano do Ensino Fundamental.

\subsubsection{Aplicativo I: Math X Undead}

Neste aplicativo, os alunos podem treinar as operações em um jogo, no qual é necessário acertar o resultado de uma operação, que está em uma das três alternativas disponibilizadas, para destruir os zumbis e avançar os níveis. A cada nível aumenta-se a dificuldade, e as operações ficam mais complexas. A Figura 1 mostra a interface do aplicativo à esquerda e o início de um jogo no primeiro nível do aplicativo à direita.

Figura 1 - Tela inicial do Aplicativo (à esquerda) e um nível do aplicativo (à direita).

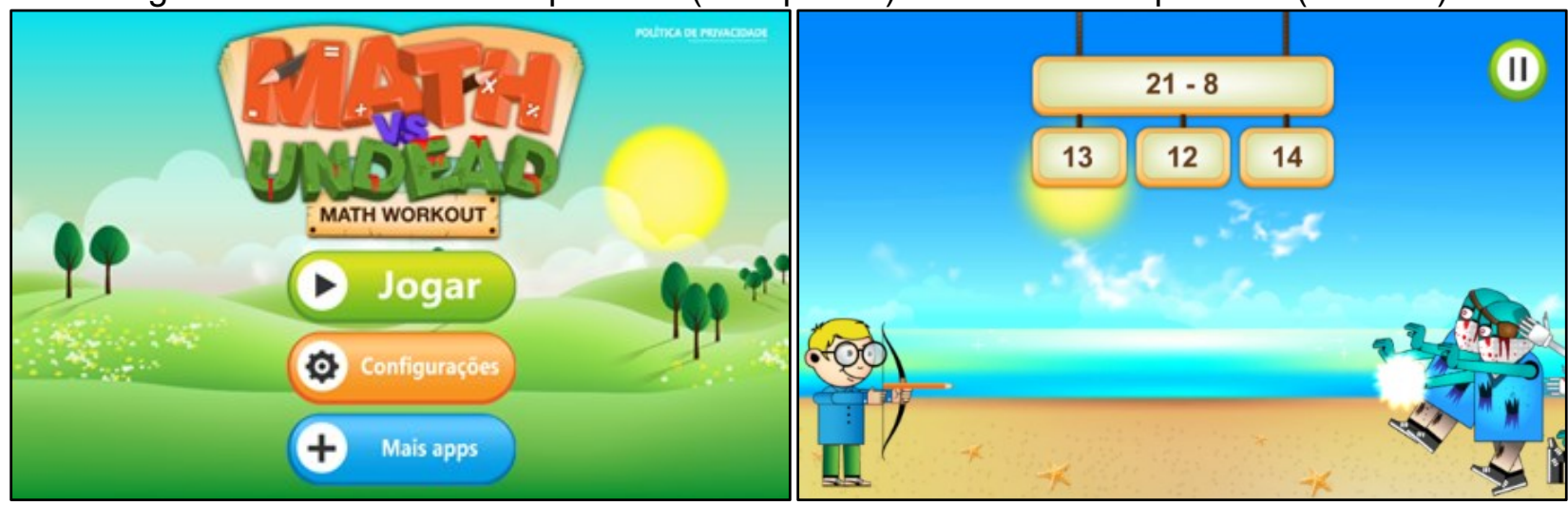

Fonte: Peaksel Games (2017a).

Acertando a alternativa, o jogador destrói os zumbis, errando, eles se aproximam cada vez mais. O chute não é uma boa alternativa, pois a cada erro a operação é trocada, e os zumbis continuarão se aproximando. O jogo é divertido e competitivo. O objetivo é passar todos os 30 níveis com o melhor desempenho possível.

\subsubsection{Aplicativo II: Math Duel}

Neste jogo, a disputa é entre duas pessoas, que escolhem uma das três alternativas que seja a resposta correta da operação, até um dos dois conseguirem 10 pontos, que significam 10 respostas corretas, e assim vencer o jogo. A Figura 2 mostra a interface do aplicativo à esquerda e o início de um jogo no primeiro nível do aplicativo à direita. 
Figura 2 - Tela inicial do Aplicativo (à esquerda) e um nível do aplicativo Math Duel (à direita).

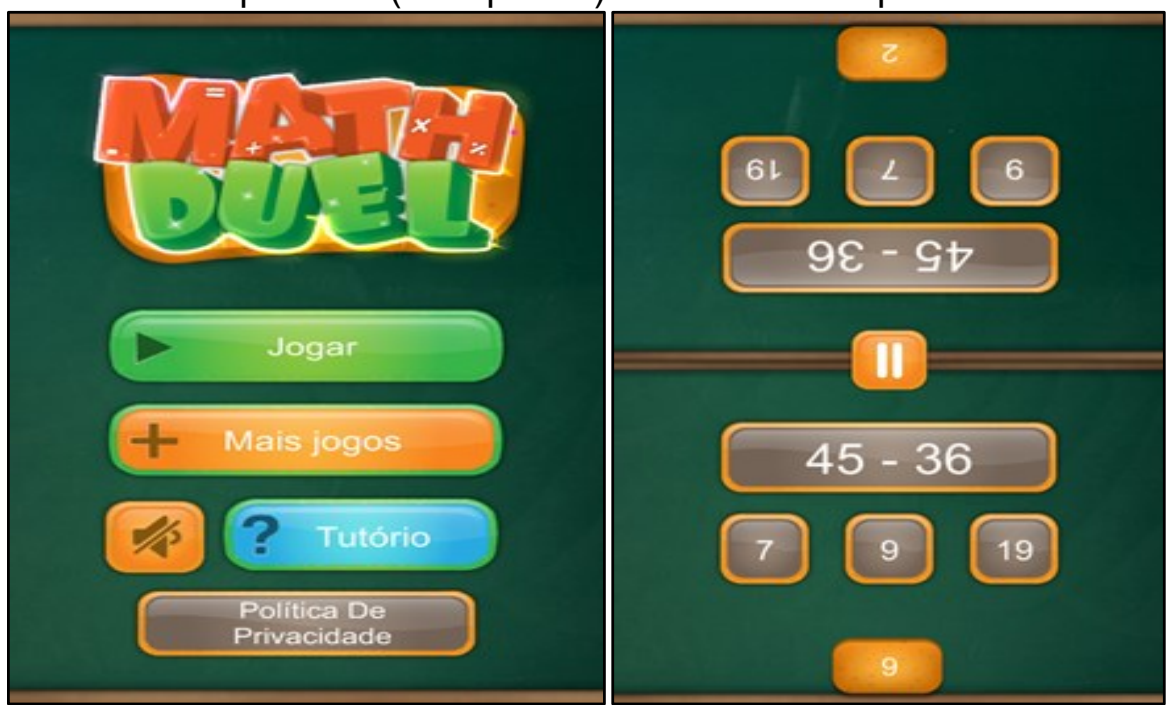

Fonte: Peaksel Games (2017b).

\subsubsection{Aplicativo III: Math Race}

Este aplicativo se baseia em um jogo de corrida de carro, similar ao da Fórmula 1, em uma pista de algumas curvas, onde o jogador é desafiado pela máquina, o "Mr.X". É possível escolher o carro de preferência e nomeá-lo. A prova tem cinco voltas e a cada resposta correta, a aceleração do carro aumenta. As perguntas são operações aritméticas com seis alternativas para escolha. A Figura 3 mostra a interface do aplicativo à esquerda e o início de um jogo no primeiro nível do aplicativo à direita.

Figura 3 - Tela inicial do Aplicativo (à esquerda) e um nível do aplicativo Math Race (à direita).

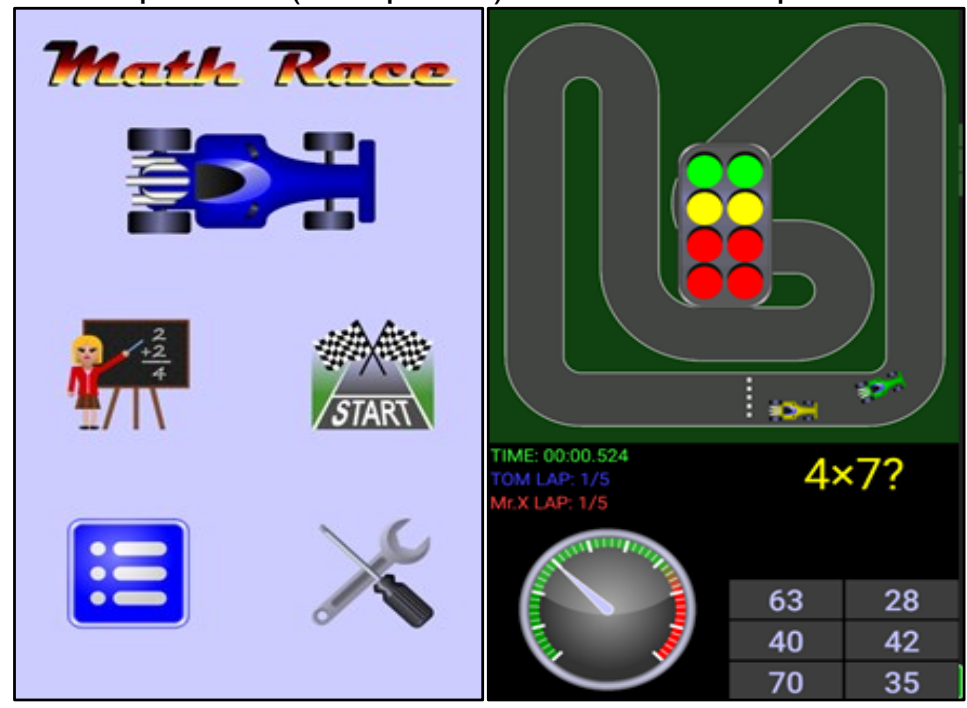

Fonte: Peaksel Games (2017b).

Para ganhar a corrida, é necessário ser mais rápido que o computador, o que não é simples, pois a cada resposta errada, o carro é desacelerado. O jogo é um desafio saudável e o 
jogador logo percebe que tem mais sucesso quando raciocina ao invés de "chutar", induzindo o discente a utilizar o raciocínio lógico corroborando com o Cálculo Mental.

\subsubsection{Aplicativo IV: Math vs Dinosaurs}

Esse aplicativo tem uma excelente interface gráfica, cheio de etapas e fases, nas quais o jogador tem que resolver operações matemáticas para acertar os adversários e gradualmente passar as fases. O jogador escolhe entre três alternativas aquela que considera correta. Se acertar, elimina o opressor ou algum animal selvagem, se errar, esses personagens se aproximam cada vez mais do jogador. Quando se aproxima ao máximo, o jogador é eliminado da fase. A Figura 4 mostra a interface do aplicativo à esquerda e a tela inicial à direita.

Figura 4 - Interface do aplicativo (à esquerda) e a tela inicial do aplicativo Math vs Dinosaur (à direita).

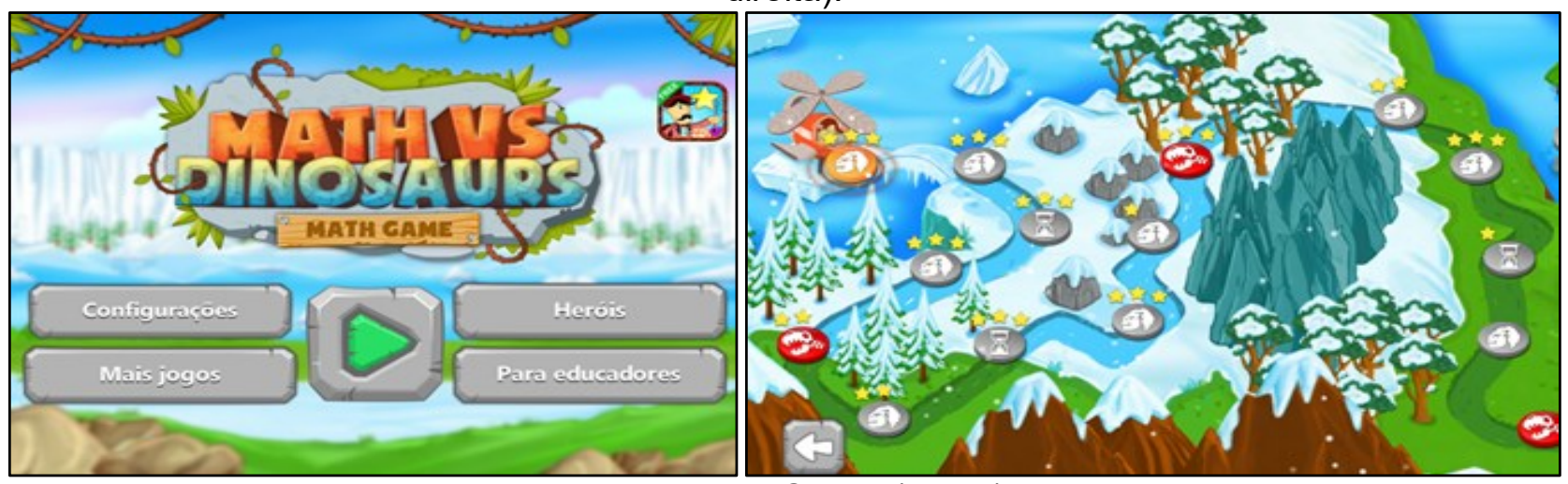

Fonte: Peaksel Games (2017c).

A Figura 5 apresenta algumas etapas do aplicativo no nível fácil.

Figura 5 - Exemplos de operações sugeridas pelo aplicativo Math vs Dinosaur.

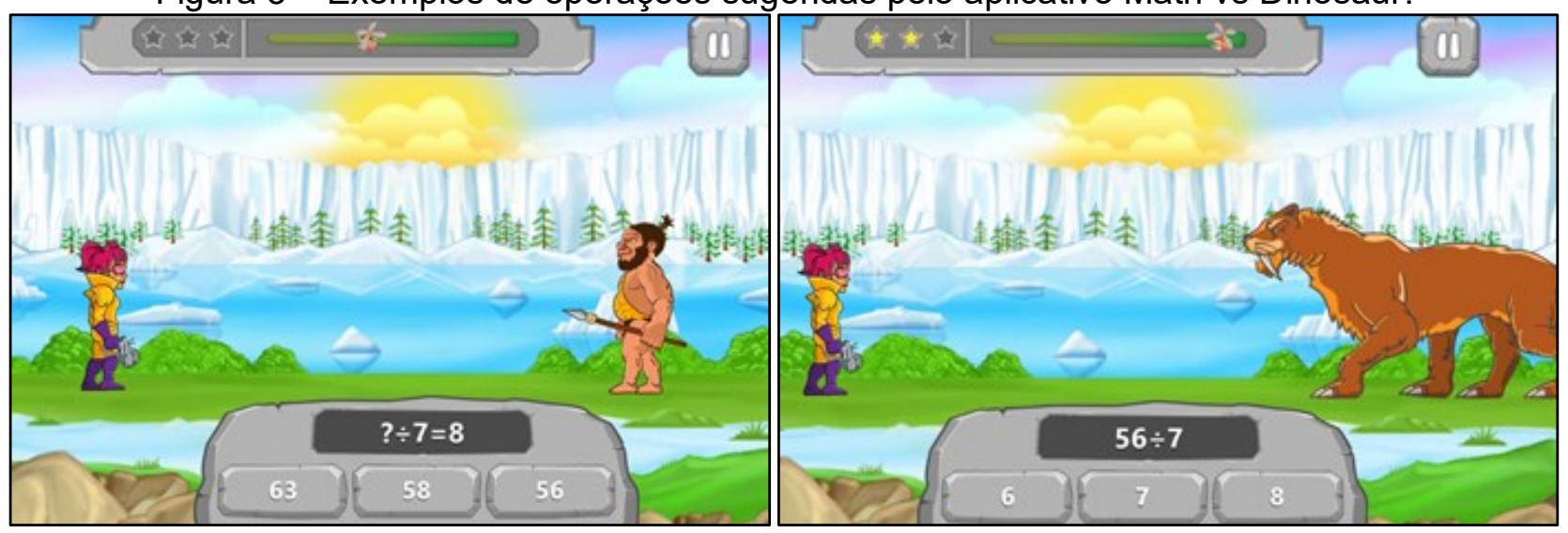

Fonte: Peaksel Games (2017c).

\subsubsection{Aplicativo V: Math Creatures From Space}

Neste jogo, é preciso acertar as operações propostas para exterminar as criaturas do espaço e assim vencer todas as etapas. São quatro fases, cada fase possui nove níveis. Em 
todos as fases são trabalhadas as quatro operações simultaneamente. É um jogo interessante com um nível mais avançado, pois o tempo conta nas jogadas e a resposta certa precisa ser digitada. Várias operações são lançadas na mesma tela, veja a Figura 6, e o tempo para responder diminui a cada fase avançada.

Figura 6 - Fases do aplicativo Math Creatures From Space.

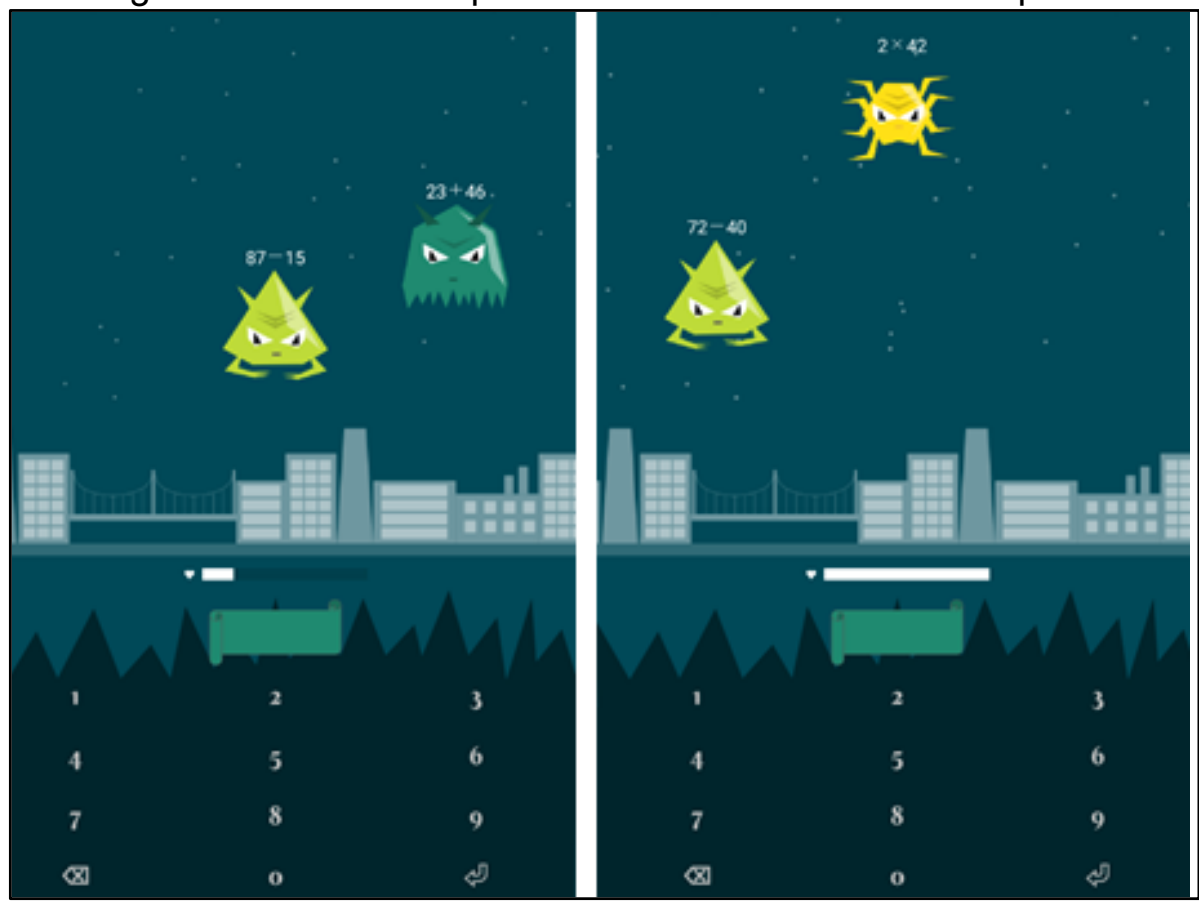

Fonte: Math Creatures from Space (2017).

Além dos aplicativos, já mencionados nesta pesquisa, também foram utilizados outros três jogos voltados para o Cálculo Mental, "Second Grade Math Lite", "Math Games" e "Truques Matemáticos", que possuem a mesma analogia dos demais, e poderão ser vistos com mais detalhes em Barreto (2017).

\subsection{Aplicação e Etapas da Pesquisa}

Esta pesquisa foi realizada na Escola Municipal Professor Samuel Brust, situada a rua Justiniano Vieria, S/N, Bairro Fronteira, na cidade de Macaé, Estado do Rio de Janeiro. Foram escolhidas duas turmas do $6^{\circ}$ ano de escolaridade, a F6-209, com 31 alunos matriculados, mas com 27 alunos ativos, e a F6-210, com 31 alunos matriculados, e 25 alunos ativos.

\subsubsection{Etapas da Pesquisa}

A pesquisa foi desenvolvida durante 19 aulas de 50 minutos cada, totalizando 950 minutos de atividade. Todo o processo foi dividido em sete etapas como vemos na Tabela 1. 
Tabela 1 - Etapas da Pesquisa.

\begin{tabular}{|c|c|c|c|c|c|c|}
\hline $\begin{array}{l}1^{a} \text { Etapa } \\
\text { (1 aula) }\end{array}$ & $\begin{array}{l}2^{a} \text { Etapa } \\
\text { (4aulas) }\end{array}$ & $\begin{array}{c}3^{a} \text { Etapa } \\
\text { (1 aula) }\end{array}$ & $\begin{array}{l}4^{a} \text { Etapa } \\
\text { (6 aulas) }\end{array}$ & $\begin{array}{l}5^{a} \text { Etapa } \\
\text { (4 aulas) }\end{array}$ & $\begin{array}{l}6^{a} \text { Etapa } \\
\text { (2 aulas) }\end{array}$ & $\begin{array}{c}7^{a} \text { Etapa } \\
\text { (1 aula) }\end{array}$ \\
\hline $\begin{array}{l}\text { 1. Diálogo } \\
\text { informal com } \\
\text { a turma. } \\
\text { 2. Aplicação } \\
\text { do } \\
\text { questionário } \\
\text { investigativo. }\end{array}$ & $\begin{array}{l}\text { 1. } \\
\text { Apresentação } \\
\text { inspirada em } \\
\text { Afonso } \\
\text { (1994). } \\
\text { 2. Utilização } \\
\text { do aplicativo } \\
\text { Math x } \\
\text { Undead. } \\
\text { 3. Aplicação } \\
\text { da Gincana I, } \\
\text { utilizando o } \\
\text { aplicativo } \\
\text { math duel. }\end{array}$ & $\begin{array}{l}1 . \\
\text { Utilização } \\
\text { do } \\
\text { aplicativo } \\
\text { Second } \\
\text { Grade } \\
\text { Math Lite. }\end{array}$ & $\begin{array}{l}\text { 1. Utilização } \\
\text { dos aplicativos } \\
\text { Math Race, } \\
\text { Math Games, } \\
\text { Matemática vs } \\
\text { Dino (adição e } \\
\text { subtração). } \\
\text { 2. Utilização } \\
\text { dos aplicativos } \\
\text { Math Race, } \\
\text { Multiplications } \\
\text { Games, } \\
\text { Matemática vs } \\
\text { Dino (divisão e } \\
\text { multiplicação). }\end{array}$ & $\begin{array}{l}\text { 1. } \\
\text { Apresentação } \\
\text { dos slides de } \\
\text { RPRM } \\
\text { (2013a, } \\
2013 b, 2013 c, \\
2014) \text {, } \\
\text { relembrando } \\
\text { as estratégias } \\
\text { do Cálculo } \\
\text { Mental. } \\
\text { 2. } \\
\text { Apresentação } \\
\text { de slides com } \\
\text { estratégias do } \\
\text { Cálculo } \\
\text { Mental } \\
\text { sugeridas } \\
\text { pelo aplicativo } \\
\text { Truques } \\
\text { Matemáticos. }\end{array}$ & $\begin{array}{l}1 . \\
\text { Aplicação } \\
\text { da } \\
\text { Gincana } \\
\text { II, } \\
\text { utilizando } \\
\text { o } \\
\text { aplicativo } \\
\text { Math } \\
\text { Creatures } \\
\text { From } \\
\text { Space. }\end{array}$ & $\begin{array}{l}\text { 1. Os alunos } \\
\text { respondem ao } \\
\text { último } \\
\text { questionário } \\
\text { que analisa as } \\
\text { opiniões sobre } \\
\text { o trabalho } \\
\text { desenvolvido } \\
\text { ao longo da } \\
\text { pesquisa. } \\
\text { 2.Os discentes } \\
\text { avaliam os } \\
\text { conhecimentos } \\
\text { adquiridos em } \\
\text { relação às } \\
\text { operações } \\
\text { trabalhadas no } \\
\text { questionário } \\
\text { inicial. }\end{array}$ \\
\hline
\end{tabular}

Fonte: Dados da pesquisa.

\section{Resultados}

Nesta seção, serão apresentadas as análises dos dados obtidos através do questionário inicial e final, levando em consideração a utilização dos aplicativos lúdicos, visando as estratégias do Cálculo Mental. Os resultados apresentados comprovaram a eficiência da metodologia aplicada.

\subsection{Questionário Inicial}

O questionário inicial (Pré-teste) consta de 10 questões fechadas e abertas. As duas primeiras questões são fechadas e têm a finalidade de saber sobre a relação pessoal do aluno com a matemática. As questões 3 e 4 também são fechadas e procuram identificar o quanto os alunos fazem operações aritméticas fora da escola, em situações cotidianas, e se os mesmos realizam essas operações mentalmente. Na questão 5, o intuito era investigar o conhecimento do discente em relação a alguns conceitos aritméticos. Nas questões 6 a 9, procuravam avaliar o discente em relações as operações com resolução de problemas. Os estudantes tiveram a orientação de fazer os cálculos mentalmente, sem a realização dos algoritmos. Por fim, a última questão foi aberta e teve como objetivo analisar o sentimento dos alunos sobre a sua relação pessoal com a matemática. Detalhes específicos e mais abrangentes sobre o questionário investigativo (Pré-teste) poderá ser visto na íntegra no trabalho de Barreto (2017).

A Figura 7 apresenta as questões 3 e 4 do questionário inicial e investigativo (Pré-teste) seguido dos resultados, apresentados nos gráficos da Figura 8. 
Figura 7 - Questões 3 e 4 do questionário inicial.

3) Você faz contas fora da escola?
( ) SIM
( ) NÃO
( ) ÀS VEZES

4) Você consegue fazer contas "de cabeça"?
( ) SIM
( ) NÃO
( ) MAIS OU MENOS

Fonte: Dados da pesquisa.

Figura 8 - Resultado da Questão 3 (à esquerda) e resultado da questão 4 (à direita).

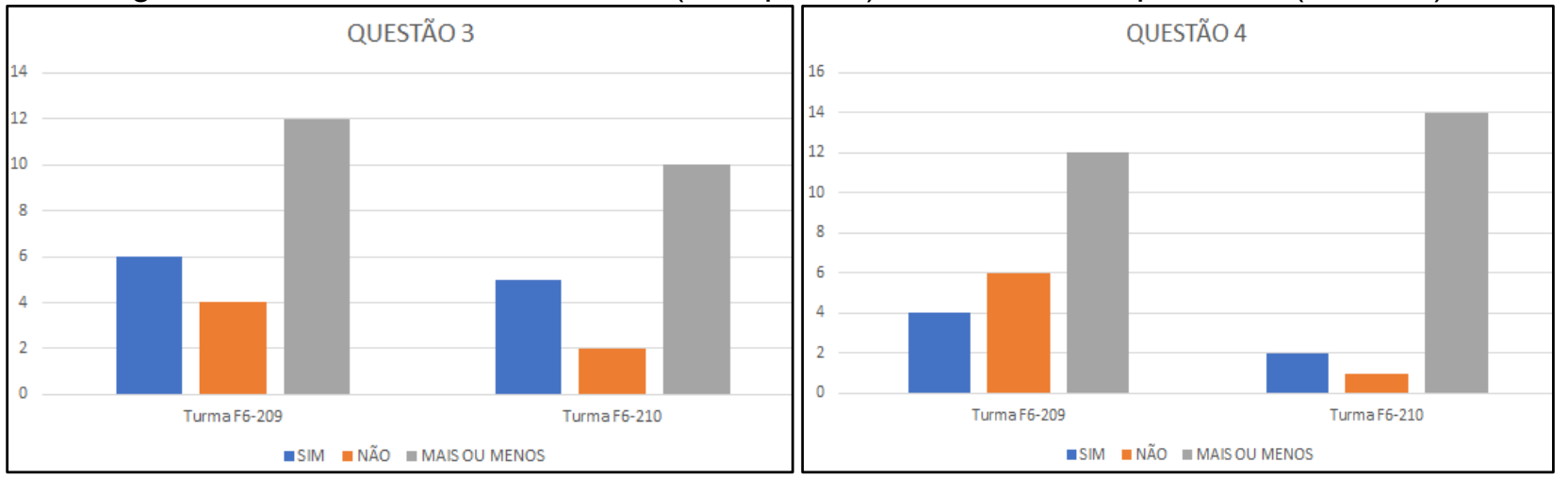

Fonte: Dados da pesquisa.

$\mathrm{Na}$ Figura 8, percebemos uma insegurança ou indecisão dos alunos a respeito dos cálculos mentais, principalmente em relação à turma F6-209.

\subsection{Análise do Questionário Final}

No questionário investigativo final (Pós-teste) também constam 10 questões fechadas e abertas. A primeira questão teve como objetivo saber se houve progresso na confiança dos discentes na realização dos cálculos mentais. Destaca-se que o resultado foi muito satisfatório, ver Barreto (2017).

A questão 2 tem o intuito de mostrar se os estudantes acreditam que o uso das ferramentas tecnológicas, os tablets e aplicativos, foram eficazes para o seu desenvolvimento no Cálculo Mental. Os resultados para este item foram unânimes para a turma F6-209, na qual todos reconheceram que a metodologia aplicada foi eficaz. A turma F6-210, apesar de não serem unânimes em relação ao "sim", nenhum aluno afirmou a ineficácia da tecnologia inserida.

$\mathrm{Na}$ questão 3, tivemos o objetivo de saber a preferência dos estudantes em relação aos aplicativos utilizados na pesquisa, como mostra o gráfico da Figura 9. O jogo Math Race foi escolhido como preferência de ambas as turmas. 
Figura 9 - Resultado da Questão 3 do questionário final.

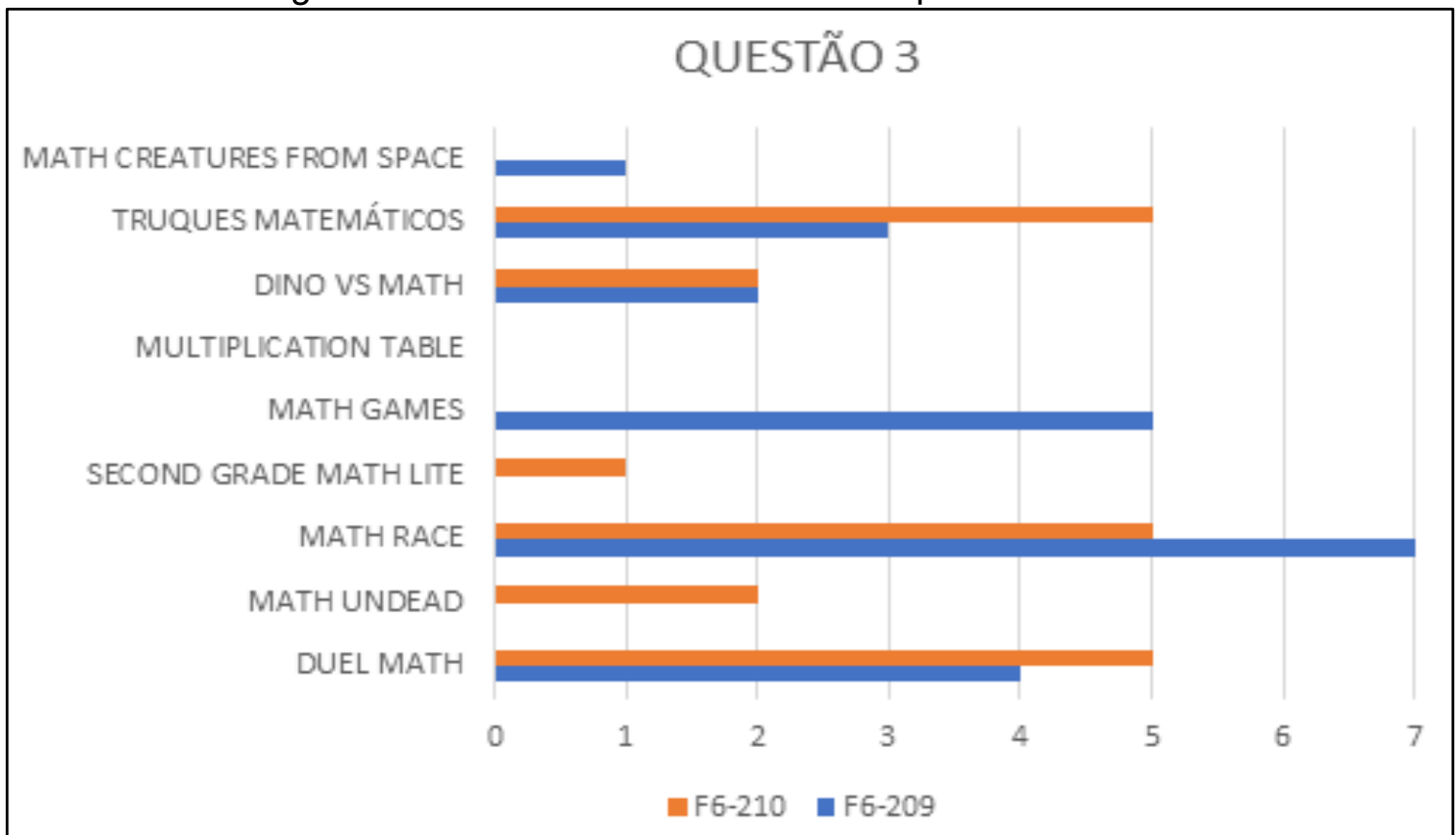

Fonte: Dados da pesquisa.

As questões 5 a 9 procuravam avaliar o discente em relação às operações com resolução de problemas, semelhante ao questionário inicial. A questão 5 é similar a questão 6 do questionário inicial. Os gráficos da Figura 10 mostram a evolução de ambas as turmas no quesito Cálculo Mental.

Figura 10 - Comparativo entre os resultados das questões 5 e 6 respectivamente dos questionários final e inicial - Turma F6-209 (à esquerda) e Turma F6-210 (à direita).

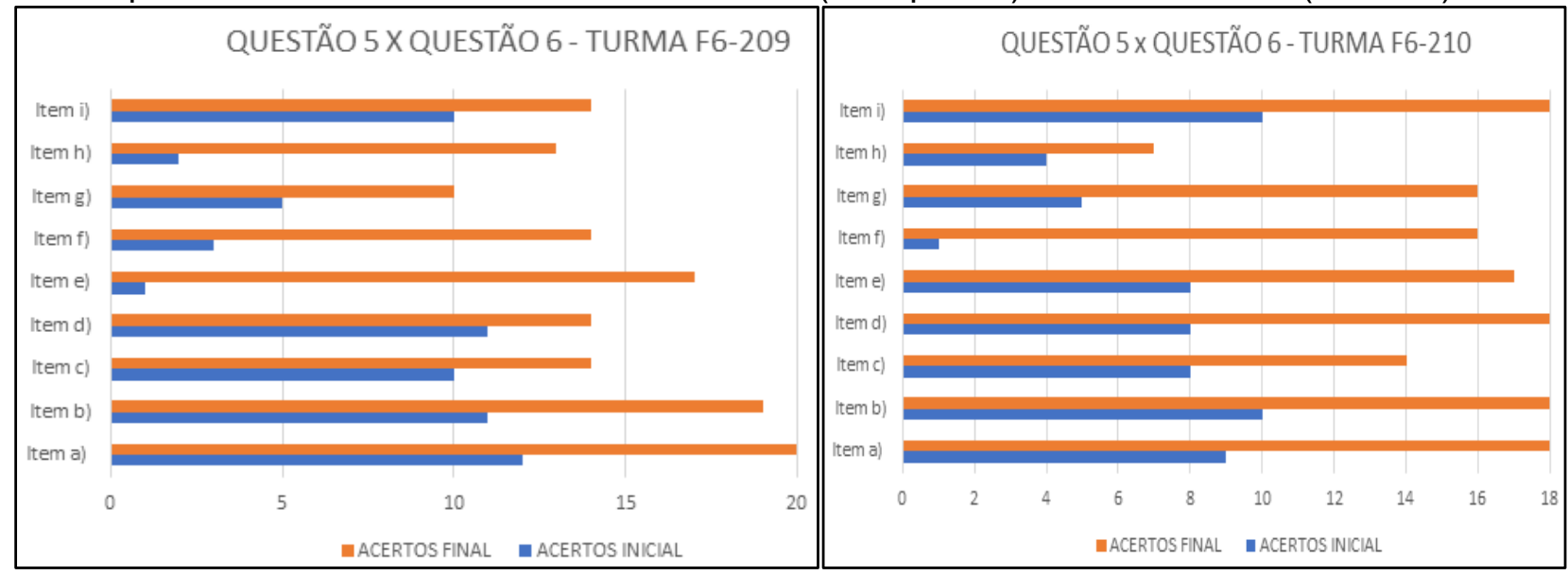

Fonte: Dados da pesquisa.

A evolução dos resultados foi muito significativa em todos os itens, comprovando a eficácia do uso de aplicativos como ferramenta de ensino do Cálculo Mental. Por fim, fizemos um comparativo, Figura 11, entre as questões similares do questionário final e inicial. 
Figura 11 - Comparativo dos resultados dos questionários final e inicial - Turma F6-209 (à esquerda) e Turma F6-210 (à direita).

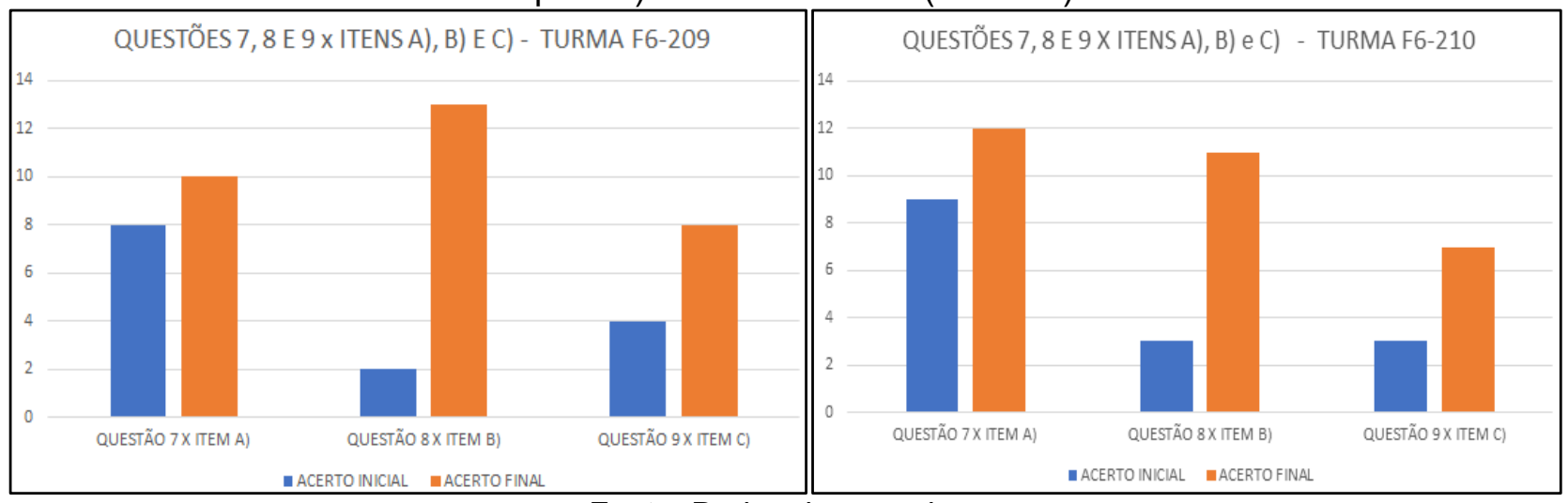

Fonte: Dados da pesquisa.

Ao analisar os comparativos, pôde-se perceber o quanto o trabalho impactou de forma positiva para ampliar o conhecimento dos estudantes. Muitos deles- não tinham um repertório mínimo de realizações aritméticas simples, mas agora organizam seus pensamentos e reconhecem os benefícios de exercitar seu raciocínio lógico.

\section{Considerações Finais}

Sabemos dos inúmeros desafios que a educação atual apresenta. Toda essa dificuldade foi o que impulsionou esta pesquisa desde o início, especialmente o cenário crítico nacional da educação matemática, mais especificamente a situação das turmas de sextos anos do município de Macaé, que apresentam baixo rendimento em matemática.

Para amenizar essa real situação, apostamos na tecnologia e no seu impacto atual no sistema educacional, através das NTIC. A escolha de se trabalhar com o tablet como dispositivo foi acertada, na medida que não foi preciso um grande aparato tecnológico para implementar a pesquisa, apenas baixar os aplicativos quando se teve internet disponível e carregar os aparelhos previamente. Já a seleção dos aplicativos exigiu uma pesquisa intensa, pois não há muitas informações sobre como eles podem contribuir para a aprendizagem, além de haver uma infinidade de opções a serem escolhidas. Por isso, foi necessário baixá-los na playstore, testá-los e encaixá-los no planejamento da pesquisa.

O lúdico foi fundamental para as atividades, pois trouxe leveza para as aulas. Os alunos estavam extremamente interessados em utilizar os recursos, o que percebemos nos resultados do pós teste, onde a maioria dos alunos concordou que os aplicativos trouxeram uma melhora em seu raciocínio, e que o uso da tecnologia foi muito benéfico para o aprendizado.

Por fim, concluímos que este trabalho trouxe muitos benefícios para as turmas participantes, aprimoramento do aprendizado, da confiança e do interesse desses alunos. Destaca-se ainda que aulas diferenciadas estimulam o processo de ensino aprendizagem dos 
nossos alunos, provando que é viável investir em nossa prática, incrementá-la, modernizá-la, proporcionando um aprendizado interessante, descontraído e estimulante.

\section{Referências}

AFONSO, Bernanrdo Gómez. Los métodos de cálculo mental en el contexto educativo: Un análisis en la formación de profesores. 1994. Tese (Tesis Doctoral) - Departament de Didàctica de la Matemática, Facultat de Matemàtiques, Universitat de València, 1994.

AMADO, N. M. P.; CARREIRA, S. P. G. Recursos Tecnológicos no Ensino e Aprendizagem da Matemática. In: DULLIUS, M. M.; QUARTIERI (Orgs.). Explorando a matemática com aplicativos computacionais: anos iniciais do Ensino Fundamental. Lajeado: UNIVATES, 2015.

BARRETO, L. S. F. Aplicativos Gratuitos como Ferramenta Tecnológica no Desenvolvimento do Cálculo Mental. 2017. 148 f. Dissertação (Mestrado em Matemática) - Programa de PósGraduação Profissional em Matemática. Universidade Estadual do Norte Fluminense Darcy Ribeiro, Campos dos Goytacazes, RJ, 2017.

BRASIL. Ministério da Educação e do Desporto do Brasil. Parâmetros Curriculares Nacionais: Matemática $1^{\text {a }}$ a $4^{\mathrm{a}}$ série. v. 3. Brasília, DF: MEC, 1997.

CARREIRA, S. P. G.; AMADO, N. M. P. Explorando a Matemática com Aplicativos Computacionais. Lajeado: UNIVATES, 2015.

CERQUEIRA, V. M. M. de. Resiliência e tecnologias digitais móveis no contexto da educação básica: senta que lá vem a história. 2014. 289 f. Tese (Doutorado em Educação) Programa de Estudos Pós-Graduados em Educação: Currículo, Pontíficia Universidade Católica de São Paulo, 2014.

CLARK-WILSON, A.; OLDKNOW, A.; SUTHERLAND, R. E. Digital technologies and mathematiques education. Joint Mathematical Council of the United Kingdom. 2011. Disponivel em: <http://www.jmc.org.uk/documents/JMC Report Digital Technologies 2011.pdf>. Acesso em: 28 ago. 2017.

CRESWELL, J. W. Projeto de pesquisa: métodos qualitativos, quantitativos e misto. 2. ed. Porto Alegre: Artmed, 2007.

FONSECA, J. J. S. da. Metodologia da pesquisa científica. Universidade Estadual do Ceará, Fortaleza, 2002.

LEHFELD, N. A. S.; BARROS, A. J. P. Projeto de pesquisa: propostas metodológicas. Petrópolis/RJ: Vozes, 1991.

MATH CREATURES FROM SPACE. Aplicativo. 2017. Disponível em: <https://play.google.com/store/apps/details?id=br.net.btco.pf913>. Acesso em: 18 ago. 2017.

PARRA, C. Cálculo mental na escola primária. Didática da matemática: reflexões psicopedagógicas. Porto Alegre: Artmed, 1996.

PEAKSEL GAMES. Math X Undead. 2017. Disponível em: <https://www.peaksel.com/mathgames/math-vs-undead-math-workout/>. Acesso em: 18 ago. 2017.

PEAKSEL GAMES. Math Duel. 2017. Disponível em: <https://www.peaksel.com/mathgames/math-duel-2-player-math-game/>. Acesso em: 18 ago. 2017. 
PEAKSEL GAMES. Math vs Dinosaurs. 2017. Disponível em: <https://www.peaksel.com/mathgames/math-vs-dinosaurs/>. Acesso em: 18 ago. 2017.

RALSTON, A. Fim à aritmética de papel e lápis. Educação e Matemática, v. 59, p. 36-41, 2000.

RPRM. Estratégias de cálculo mental: adição. 18 out. 2014. Disponível em:

<https://prezi.com/jv ht5hgxznt/estrategias-de-calculo-mental-adicao/>. Acesso em: 28 jul. 2018.

RPRM. Estratégias de cálculo mental: subtração. 13 out. 2013. Disponível em:

$<$ https://prezi.com/jefe3tp9xsyl/estrategias-de-calculo-mental-subtracao/>. Acesso em: 28 jul. 2018.

RPRM. Estratégias de cálculo mental: multiplicação. 13 out. 2013. Disponível em:

$<$ https://prezi.com/mabhxftcnswq/estrategias-de-calculo-mental-multiplicacao/>. Acesso em: 28 jul. 2018.

RPRM. Estratégias de cálculo mental: divisão. 13 out. 2013. Disponível em:

$<$ https://prezi.com/skgogy9py30w/estrategias-de-calculo-mental-divisao/>. Acesso em: 28 jul. 2018.

TATON, R. O cálculo mental. Trad. VIDEIRA, M. A. Lisboa: Arcádia, 1969.

VALENTE, W. R. Livros Didáticos de Matemática e as Reformas Campos e Capanema. In: ENCONTRO NACIONAL DE EDUCAÇÃO MATEMÁTICA, 8. 2004, Recife. Anais... Sociedade Brasileira de Educação Matemática, 2014. p. 1-7. 